\title{
Penetrating Injuries to the Colon and Rectum
}

\author{
Marc D. Trust ${ }^{1} \cdot$ Carlos V. R. Brown ${ }^{1}$
}

Published online: 11 April 2015

(C) Springer International Publishing AG 2015

\begin{abstract}
The management of colon and rectal injuries has evolved greatly over the last several decades. Once known to have significant mortality, the implementation of mandatory diversion in the 1940s drastically improved outcomes. Since then, treatment strategies have now shifted towards primary repair as a safe option for the majority of injuries. When wounds are more destructive, resection and primary anastomosis are usually appropriate in most situations. Management of penetrating colon injuries is more complex in the setting of damage control surgery and may require difficult decisions regarding timing of anastomosis. Rectal injuries were also historically known to have significant morbidity until diversion was implemented. Extraperitoneal injuries are still treated in a similar fashion, while intraperitoneal injuries are managed using the same principles as colon injuries. This article will review the management of penetrating colon and rectal injuries with focus on literature that has been published over the last 3 years.
\end{abstract}

Keywords Penetrating trauma $\cdot$ Colon injuries $\cdot$ Rectal injuries $\cdot$ Abdominal trauma $\cdot$ Damage control laparotomy

This article is part of the Topical Collection on Penetrating Injuries to Hollow Abdominal Viscera

Marc D. Trust

mdtrust@seton.org

1 Department of Trauma Services, University Medical Center Brackenridge, Dell Medical School at The University of Texas at Austin, 601 E. 15th St., Austin, TX 78701, USA

\section{Introduction}

The trauma surgeon does not commonly encounter colorectal injuries. Civilian data report a $1-3 \%$ incidence, while it is more common in military settings at about 5-10\% [1]. The colon is the second (after small bowel) most commonly injured organ after gunshot wounds and the third (after liver and small bowel) most common after anterior abdominal stab wound. Historically, these injuries resulted in extremely high mortality, approximately $60 \%$ during World War I [2•]. A major advance in the treatment of colon trauma came with the advent of proximal diversion by Ogilvie. Use of this technique during World War II saw much lower morbidity and mortality rates compared to previous strategies $[3 \bullet, 4]$. Treatment subsequently evolved to include exteriorization of the injured segment of colon after primary repair, a technique that has since been abandoned. This practice involved closure of a wound and exteriorizing that segment of colon for several days. An intact repair at that time was returned to the abdomen, while failure then required diversion [2•]. The 1970s saw the next major paradigm shift when Stone and Fabian conducted the first randomized, prospective study comparing proximal diversion to primary repair. Their findings showed that primary repair was not only safe, but also associated with better outcomes when used in certain situations [4-6]. Over the last three decades, a great deal of literature has not only validated these findings, but also expanded on this principle so much that diversion is now applied in only a few specific situations.

\section{Destructive Versus Non-Destructive Injuries}

Colon injuries can generally be categorized into destructive versus non-destructive types. Most authors describe non- 
destructive lesions as those involving less than $50 \%$ of colon wall circumference and lack of devascularization. A great deal of literature published over the last 30 years supports primary repair of these injuries with lower complication rates compared to diversion. Destructive injuries, on the other hand, are described as involvement of greater than $50 \%$ of bowel wall circumference, devascularized segments, complete transection, or significant loss of tissue $[2 \bullet, 7 \bullet]$. Management of destructive colon injuries with diversion versus resection with primary anastomosis has received a great deal of attention in the literature. Several small studies have suggested that resection with anastomosis is a safe option in patients without significant risk factors for anastomotic leak such as high transfusion requirement, hypotension, associated medical illness, or penetrating abdominal trauma index greater than $25[8,9]$. A 2001 multicenter, prospective AAST-sponsored study comparing diversion versus resection and anastomosis for destructive penetrating colon injuries failed to show any difference in complication rates between these management options, but did note a higher mortality in patients who received diversion ( 0 vs. $4 \%$ ). They concluded that resection with anastomosis was the better management option given the worse quality of life associated with diversion [10]. Morbidity associated with a second operation for reversal must also be considered when choosing between these options [3•].

As much of the literature that supports our modern day strategies for treatment of colon injures developed over the last 35 years, the scope of this discussion focuses on the most recent data. As previously mentioned, destructive colon injuries have proven to be safely managed with primary repair and anastomosis, except in patients with risk factors for anastomotic breakdown. In 1994, Stewart et al. reported a $42 \%$ leak rate in patients who had a six-unit or higher transfusion requirement or a medical illness, compared to $3 \%$ who had neither of these risk factors [8]. The same group aimed to improve on these outcomes by establishing an algorithm for management of destructive injuries in high-risk patients. Using this algorithm, all non-destructive injuries are repaired primarily while destructive injuries in the setting of risk factors for leak are diverted, while those without risk factors are treated with resection and anastomosis. The results of this effort were published in 2002, and although they did not show a statistically significant decrease in complication rates, a decreased number of colostomies in low-risk patients were performed over that time period ( 9 vs. $31 \%$ ) [11]. In 2012, the same group published 15 years of data comparing management of colon injuries before and after implementation of their algorithm. This included 291 patients, 102 of whom had destructive wounds. Resection plus anastomosis rates were similar and, although they did not reach statistical significance, colon-related complication rates did also trend downwards. Abscess formation, leak rate, and mortality all decreased compared to the prior studies. They also again noted a decrease in diverting colostomies in the low-risk group [7•] (Fig. 1).

\section{Location of Injury}

There is a long-held belief and surgical dogma that left-sided colon injuries have a higher risk of complications after anastomosis than right-sided injuries, but no study has ever demonstrated a difference in outcomes [2•]. A study by Hatch et al. published in 2013 using data from the National Trauma Data Bank evaluated outcomes stratified by mechanism, segment of colon injured, and management strategy. Although they included patients with a blunt mechanism, which is outside of the scope of this article, the study is worth discussing as it evaluated over 6000 patients. Trauma caused by a penetrating mechanism was found to have lower mortality (10.2 vs. $13.5 \%$ ), overall morbidity (19.0 vs. $22.0 \%$ ), and shorter ventilator and ICU days ( 7.7 vs. 9.1 and 8.6 vs. 9.9 days, respectively). When evaluating outcomes based on segment of colon injured, they did not appreciate any major differences in overall morbidity or mortality between locations of the colon. They did note, however, that a high percentage (36\%) of injuries was reported as "nonspecified"; thus, a strong inference cannot be made from this data. There was an overall $9 \%$ proximal diversion rate, more commonly in older and more severely injured patients. In addition, sigmoid injuries were more likely to be treated with proximal diversion. There was no distinction between destructive or nondestructive injuries, and during multivariate analyses, diversion was not found to be independently associated with worse outcomes [5].

In 2012, Sharpe et al. evaluated the effect of injury location on outcomes treated with their previously mentioned algorithm. They identified 469 patients who suffered penetrating colon injuries, the majority of which were non-destructive and amenable to primary repair. They noted that sigmoid injuries had a higher percentage of treatment with diversion $(17 \%$ compared to 8,8 , and $9 \%$, for the ascending, transverse, and descending, respectively), however did note that these patients had a higher 24-h transfusion requirement which likely placed some in this group in the high-risk arm of the algorithm that mandates diversion. When looking at complications such as intra-abdominal abscess, suture-line breakdown, and mortality, there was no statistically significant difference in rates of these complications between different locations in colon. On further analyses with multivariate logistic regression, still no predictor of poor outcome could be identified. They concluded that treatment of penetrating colon injuries with adherence to their algorithm was safe regardless of location of colonic injury [12] (Table 1).

Technical considerations for management of penetrating colon injury stratified by location are listed in Table 1 . 
Fig. 1 Proposed algorithm for management of penetrating colon injuries

Table 1 Technical considerations and associated injuries based on injured portion of colon

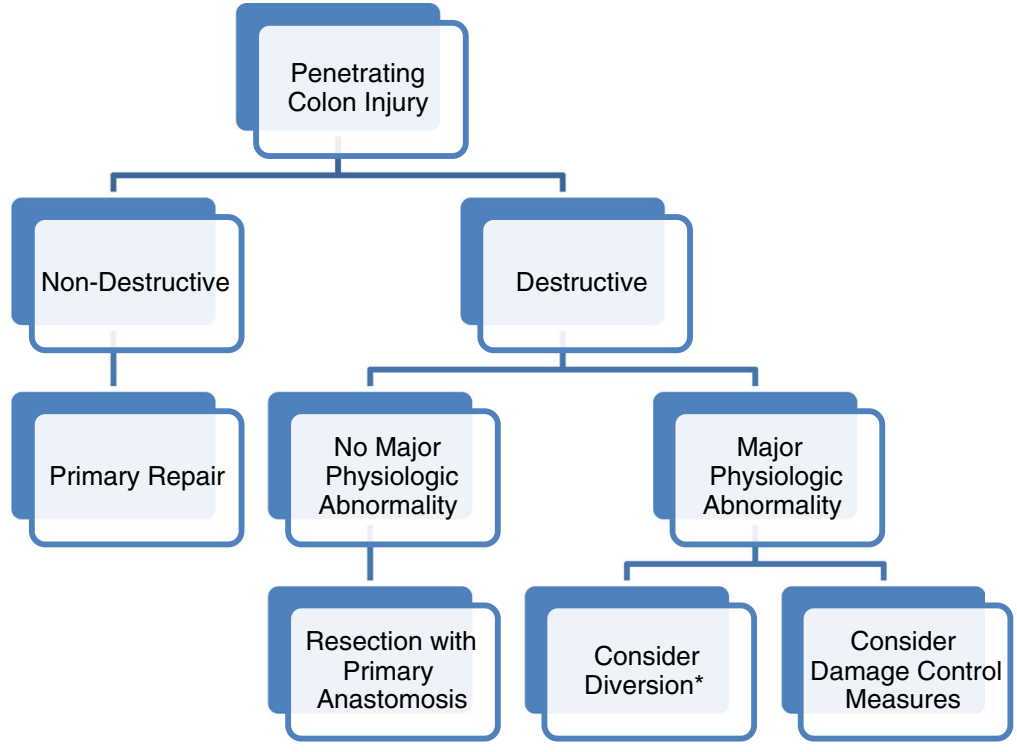

${ }^{*}$ Consideration of Diversion

- High transfusion requirement ( $\geq 6$ units)

- Prolonged hypotension

- Associated medical comorbidities

- Degree of contamination
Considerations based on location of colon injury

\begin{tabular}{|c|c|c|}
\hline Location & Technical considerations & Associated injuries \\
\hline \multirow[t]{2}{*}{ Cecum/right colon } & •Easily mobilized & -Genitourinary \\
\hline & -Ileocolic anastomoses under low tension & •Zone II retroperitoneal hematoma \\
\hline \multirow[t]{3}{*}{ Hepatic flexure } & -Inspect diaphragm & •Hepatobiliary structures \\
\hline & -Inspect duodenum and pancreas & •Duodenum \\
\hline & & •Zone II retroperitoneal hematoma \\
\hline \multirow[t]{4}{*}{ Transverse colon } & - Open gastrocolic ligament & •Zone I retroperitoneal hematomas \\
\hline & -Always inspect posterior stomach & -Stomach \\
\hline & -Drain any associated pancreatic injuries & •Pancreas \\
\hline & & -Distal portions of duodenum \\
\hline \multirow[t]{3}{*}{ Splenic flexure } & -Control splenic hemorrhage first & •Spleen \\
\hline & -Inspect diaphragm & -Tail of pancreas \\
\hline & & •Genitourinary \\
\hline \multirow[t]{2}{*}{ Descending colon } & •Easily mobilized & -Zone II retroperitoneal hematoma \\
\hline & & •Genitourinary \\
\hline \multirow[t]{3}{*}{ Sigmoid } & -Pelvic location makes exposure difficult & -Zone III retroperitoneal hematomas \\
\hline & -Always evaluate genitourinary & •Iliac vessels \\
\hline & & -Genitourinary \\
\hline
\end{tabular}




\section{Damage Control Surgery}

Since the introduction of damage control surgery in the 1980s and 1990s, its use has become commonplace for the management of unstable, high-risk patients. It has allowed surgeons to address hemorrhage and contamination, identify other lifethreatening issues, prevent or minimize the deranged physiology, and delay definitive management until the patient is more adequately resuscitated. There is a paucity of data regarding outcomes associated with destructive colon injuries treated in the setting of damage control surgery. Over the last few years, several studies have attempted to address this issue and provide evidence to help guide decisions regarding primary anastomosis versus diversion. Given the rather small patient population in question, most of the studies available are not specific to penetrating mechanisms of injury and are retrospective in nature.

In 2011, the Western Trauma Association performed a multi-institutional study looking at outcomes of all patients with enteric injuries managed with damage control surgery. Although this study has a high percentage of patients who sustained blunt trauma and included small bowel injuries, the study did include patients with penetrating colon injuries. After colonic repair or anastomosis, leak rates increased with fascial closure beyond 5 days (12 vs. $3 \%$ ) and increased with a more distal colonic anastomosis $(3 \%$ right colon, $20 \%$ transverse colon, $45 \%$ left colon) [13]. A more recent study of 247 patients, $92 \%$ of which suffered penetrating trauma, found an increased risk of colonic anastomosis leak in patients requiring damage control surgery compared to those managed with single laparotomy (13 vs. $3 \%$ ) [14]. However, complication rates similar to single laparotomy could be achieved with damage control laparotomy when successful fascial closure was completed on the first postdamage control reoperation. Delaying colonic anastomosis to subsequent operations was associated with an eightfold increase in anastomotic leak.

The Memphis group applied their established management algorithm for destructive colon injuries to a population of patients who underwent damage control laparotomy [15]. During initial damage control laparotomy, they recommend primary repair of non-destructive injuries. For destructive injuries, they recommend resection followed by either delayed anastomosis or staged diversion at subsequent operation. Decision for anastomosis or diversion was based on the presence of comorbidities or need for more than six units of blood transfusion. Patients managed with delayed anastomosis according to the algorithm had fewer anastomotic leaks (4 vs. $32 \%$ ) and lower colon-related morbidity ( 22 vs. $58 \%$ ). They concluded that destructive colon injuries in a selected patient population can safely be managed with resection and delayed anastomosis in the setting of damage control laparotomy.

\section{Rectal Injuries}

The care of rectal injuries, much like colon injuries, has evolved over the last century in large part due to experience gained from war. Proximal diversion was used around the time of World War I, followed by the addition of presacral drainage during World War II. Distal washout was then implemented during the Vietnam War [16]. This combination of treatment strategies remained the gold standard of care for rectal injuries until the 1990s when studies began challenging the benefit of these interventions $[2 \cdot]$.

The vast majority of rectal injuries are caused by a penetrating mechanism, with gunshot wounds accounting for greater than $80 \%$ and stab wounds another $5 \%$ [17]. The diagnosis of these potentially devastating injuries begins with a high level of suspicion. Penetrating wounds in the low anterior abdominal wall, buttock, pelvis, or perineum should be treated as having a rectal injury until proven otherwise. In stable patients, CT imaging (with IV contrast) can aid in determining trajectory of a penetrating wound. If the diagnosis of rectal injury remains in question, a rigid sigmoidoscopy should be performed.

\section{Intraperitoneal Injuries}

It is widely accepted that management of rectal injuries depends on whether the intra- or extraperitoneal rectums are involved. Anatomically speaking, the upper two thirds of the rectum generally make up the intraperitoneal segment, while the lower third makes up the extraperitoneal segment $[2 \bullet]$. Intraperitoneal injuries are treated in a similar manner as colon injuries, with most injuries typically amenable to primary repair without diversion. Destructive injuries will require resection with anastomosis or diversion depending on patient risk factors as mentioned above. One caveat to this approach is that low rectal anastamoses may be at higher risk for leak. Because of this, some suggest a protective diverting loop ostomy for injuries involving the distal to the mid rectum [3•] (Fig. 2).

\section{Extraperitoneal Injuries}

Extraperitoneal injuries, on the other hand, can be much more challenging given their location low in the pelvis and proximity to surrounding structures [1]. If accessible, extraperitoneal rectal injuries should be primarily repaired with or without a diverting colostomy. Extraperitoneal rectal wounds may be approached and repaired either transabdominally during laparotomy for proximal injuries or transanally for more distal injuries. However, extensive mobilization of the rectum should not be performed merely to repair an injury. 


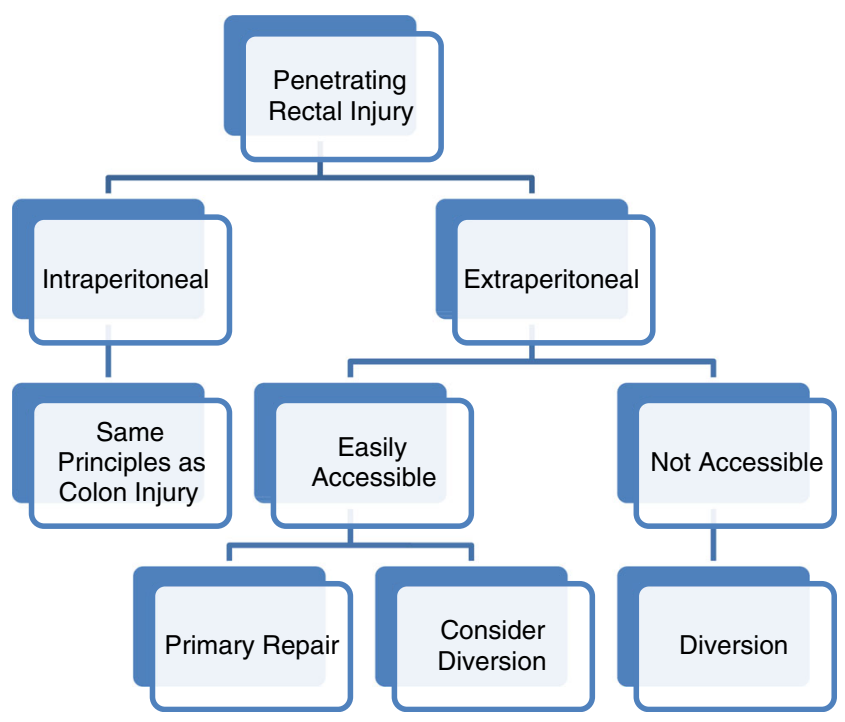

Fig. 2 Proposed algorithm for management of penetrating rectal injuries

Diverting colostomy should be considered in patients with a difficult repair or resection, shock, transfusion, degree of contamination, associated injuries, and comorbidities. If an injury is not easily accessed via the transabdominal or transanal approach, then, the treatment should consist of a diverting loop colostomy alone. If the patient does not have another indication for laparotomy, then, the diverting colostomy may be performed laparoscopically. Presacral drainage and rectal washout are no longer routinely indicated after repair of rectal injuries. Though the literature regarding management of extraperitoneal rectal injuries is limited, the most comprehensive review of the literature was published by Steele et al. in 2011 [18••]. The authors analyzed the existing literature and found that there is not enough evidence for or against routine repair of all injuries, diverting colostomy, presacral drainage, or rectal washout. Each should be applied selectively and in the context of each individual patient.

As the majority of trauma surgeons will encounter penetrating injuries from low-velocity mechanisms, it is important to be aware of the outcomes of these treatment strategies if higher velocity mechanisms are encountered. A retrospective analysis of extraperitoneal rectal injuries suffered by US soldiers in Iraq and Afghanistan published in 2013 including 57 patients noted that $100 \%$ of these injuries were treated with diversion. In addition, 11 patients were also treated with distal washout and eight patients were treated with presacral drainage. Logistic regression analysis was performed to attempt to identify a relationship between these interventions and presence or absence of a complication. Neither was shown to be statistically significant; therefore, the authors concluded that neither distal washout nor presacral drainage added any benefit to the treatment of high-velocity extraperitoneal rectal injuries [16].

\section{Conclusion}

In conclusion, the management of colon and rectal injuries has evolved greatly over the last several decades, with more recent literature expanding on that foundation. While previously treated with a "one size fits all" approach, we now know that all injuries are not created equally. Primary repair is an excellent option for the vast majority penetrating colon and rectal injuries. When wounds are more destructive, resection and primary anastomosis should be performed. In those who present more severely injured and have higher blood transfusion requirement or preexisting medical comorbidities, diversion should be considered. After damage control laparotomy, early-delayed anastomosis is also a safe option and should be performed at the initial or first reoperation. With higher complications in patients who cannot achieve early abdominal closure, diversion should also be considered. Intraperitoneal rectal injuries should be treated as colon injuries. Primary repair with or without diversion is the mainstay of treatment for extraperitoneal injuries, but colostomy alone without repair may be considered for injuries that are technically difficult to access.

\section{Compliance with Ethics Guidelines}

Conflict of Interest Marc D. Trust and Carlos V.R. Brown declare that they have no conflicts of interest.

Human and Animal Rights and Informed Consent This article does not contain any studies with human or animal subjects performed by any of the authors.

\section{References}

Papers of particular interest, published recently, have been highlighted as:

- Of importance

-• Of major importance

1. Johnson EK, Steele SR. Evidence-based management of colorectal trauma. J Gastrointest Surg. 2013;17(9):1712-9. doi:10.1007/ s11605-013-2271-9.

2. Demetriades D, Inaba K. Chapter 33: Colon and Rectal Trauma. In: Mattox K, Moore EE, Feliciano DV, editors. Trauma. 7 ed. New York City, NY: McGraw-Hill; 2013. p. 620-631. Excellent textbook chapter.

3. Martin MJ, Brown CVR. Colon and rectal trauma. In: Steele SR, Maykel JA, Champagne BJ, Orangio GR, editors. Complexities in colorectal surgery: decision-making and management. New York: Springer New York; 2013. p. 517-43. doi:10. 1007/978-1-4614-9022-7 34. Thorough textbook chapter with review of considerations for colorectal trauma management.

4. Pasquale M, Fabian TC. Practice management guidelines for trauma from the Eastern Association for the Surgery of Trauma. J 
Trauma Injury Infection Crit Care. 1998;44(6):941-56. discussion 956-7.

5. Hatch Q, Causey M, Martin M, et al. Outcomes after colon trauma in the 21st century: an analysis of the U.S. National Trauma Data Bank. Surgery. 2013;154(2):397-403. doi:10.1016/j.surg.2013.05.011.

6. Stone HH, Fabian TC. Management of perforating colon trauma: randomization between primary closure and exteriorization. Ann Surg. 1979;190(4):430-6.

7. Sharpe JP, Magnotti LJ, Weinberg JA, et al. Adherence to a simplified management algorithm reduces morbidity and mortality after penetrating colon injuries: a 15-year experience. J Am Coll Surg. 2012;214(4): 591-7. doi:10.1016/j.jamcollsurg.2011.12.029. Excellent article describing improvement of outcomes using treatment algorithm at a single institution over a 15 year time span.

8. Stewart RM, Fabian TC, Croce MA, Elizabeth Pritchard F, Minard $\mathrm{G}$, Kudsk KA. Is resection with primary anastomosis following destructive colon wounds always safe? Am J Surg. 1994;168(4): 316-9. doi:10.1016/S0002-9610(05)80156-4.

9. Murray JA, Demetriades D, Colson M, et al. Colonic resection in trauma: colostomy versus anastomosis. J Trauma. 1999;46(2):250-4.

10. Demetriades D, Murray JA, Chan L, et al. Penetrating colon injuries requiring resection: diversion or primary anastomosis? An AAST prospective multicenter study. J Trauma Injury Infect Crit Care. 2001;50(5):765-75.

11. Miller PR, Fabian TC, Croce MA, Magnotti LJ, Elizabeth Pritchard F, Minard G, et al. Improving outcomes following penetrating colon wounds: application of a clinical pathway. Ann Surg. 2002;235(6):775.
12. Sharpe JP, Magnotti LJ, Weinberg JA, et al. Impact of location on outcome after penetrating colon injuries. J Trauma Acute Care Surg. 2012;73(6):1428-33. doi:10.1097/TA.0b013e31825bff06.

13. Burlew CC, Moore EE, Cuschieri J, et al. Sew it up! A Western Trauma Association multi-institutional study of enteric injury management in the postinjury open abdomen. J Trauma Injury Infect Crit Care. 2011;70(2):273-7. doi:10.1097/TA.0b013e3182050eb7.

14. Anjaria DJ, Ullmann TM, Lavery R, Livingston $\mathrm{DH}$. Management of colonic injuries in the setting of damagecontrol laparotomy. J Trauma Acute Care Surg. 2014;76(3): 594-600. doi:10.1097/TA.0000000000000132.

15. Sharpe JP, Magnotti LJ, Weinberg JA, et al. Applicability of an established management algorithm for destructive colon injuries after abbreviated laparotomy: a 17-year experience. J Am Coll Surg. 2014;218(4):636-41.

16. Brown SR, Swisher JP, Hofmann LJ, Coviello LC, Davis KG. Surgical management and associated complications of penetrating rectal injuries sustained in Iraq and Afghanistan. Mil Med. 2013;178(11):1213-7. doi:10.7205/MILMED-D-13-00167.

17. Velmahos GC, Gomez H, Falabella A, Demetriades D. Operative management of civilian rectal gunshot wounds: simpler is better. World J Surg. 2000;24(1):114-8.

18.• Steele SR, Maykel JA, Johnson EK. Traumatic injury of the colon and rectum: the evidence vs dogma. Dis Colon Rectum. 2011;54(9): 1184-201. doi:10.1007/DCR.0b013e3182188a60. Excellent review article describing data surrounding widely followed treatment dogma. 